$11-1-2007$

\title{
Household Food Insecurity Is Inversely Associated with Social Capital and Health in Females from Special Supplemental Nutrition Program for Women, Infants, and Children Households in Appalachian Ohio
}

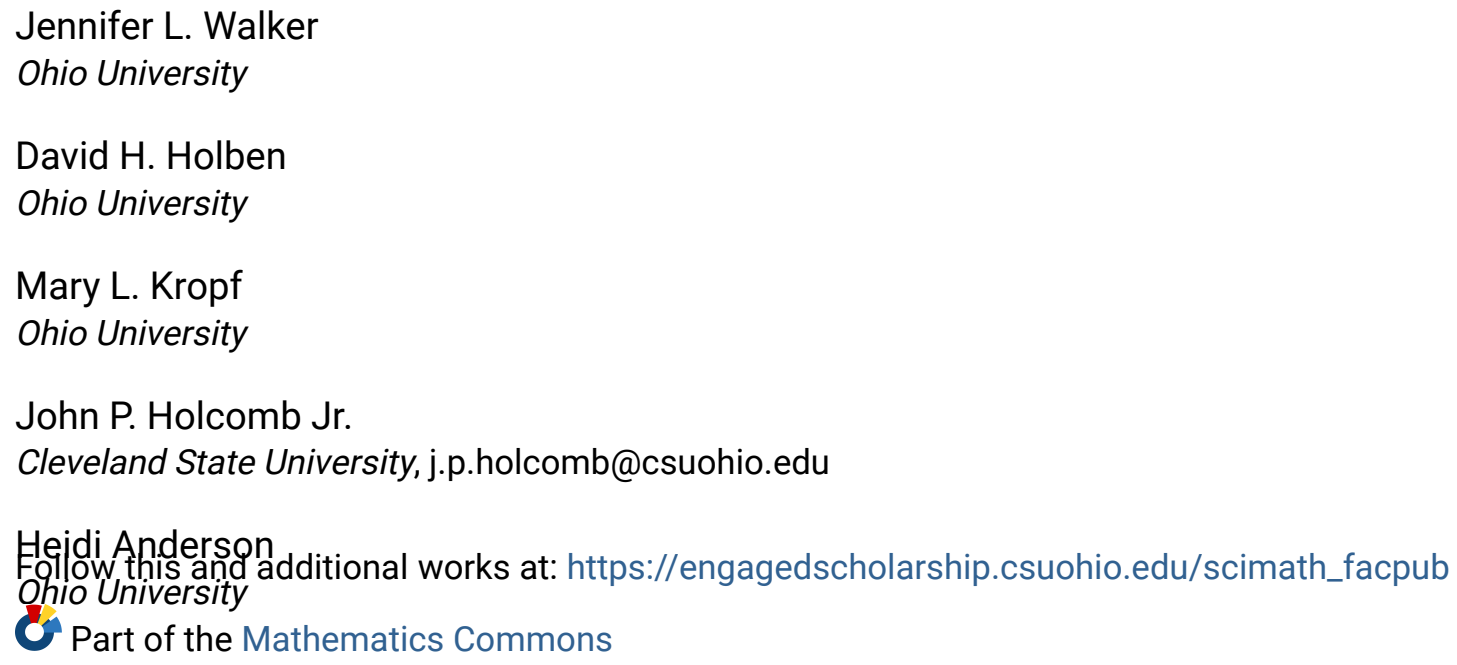

\section{Repository Citation}

Walker, Jennifer L.; Holben, David H.; Kropf, Mary L.; Holcomb, John P. Jr.; and Anderson, Heidi, "Household Food Insecurity Is Inversely Associated with Social Capital and Health in Females from Special Supplemental Nutrition Program for Women, Infants, and Children Households in Appalachian Ohio" (2007). Mathematics Faculty Publications. 200.

https://engagedscholarship.csuohio.edu/scimath_facpub/200

This Article is brought to you for free and open access by the Mathematics and Statistics Department at EngagedScholarship@CSU. It has been accepted for inclusion in Mathematics Faculty Publications by an authorized administrator of EngagedScholarship@CSU. For more information, please contact library.es@csuohio.edu. 


\section{Research and Professional Briefs}

\section{Household Food Insecurity Is Inversely Associated with Social Capital and Health in Females from Special Supplemental Nutrition Program for Women, Infants, and Children Households in Appalachian Ohio}

JENNIFER L. WALKER; DAVID H. HOLBEN, PhD, RD; MARY L. KROPF, MSHCS; JOHN P. HOLCOMB, JR, PhD; HEIDI ANDERSON, MS, MPH, RD

In the United States, food security is commonly accepted to mean "access by all people at all time to enough food for an active, healthy life" $(1,2)$. In 2005 , food insecurity was experienced by $11.0 \%$ of US households (2). Consistent with previous years, in 2005, households particularly vulnerable to food insecurity:

- were headed by a single woman with children (30.8\%);

- had children under the age of 6 years $(16.7 \%)$;

- had lower incomes (income-to-poverty ratio $<1.00$, $36.0 \%$; <1.30, 33.2\%; <1.85, 28.3\%); and

- were located in rural areas (12.0\%) (2).

Some states were also prone to food insecurity, including Ohio (12.6\%, 2003 to 2005 average) (2). Bartfield and colleagues (3) reported that food insecurity within a state is dependent upon household income, employment, and structure, as well as state-level characteristics, including food assistance program participation and tax policies.

Some regions of the United States appear be prone to food insecurity, including the Appalachian region of Ohio (4-6). This phenomenon may be due to poverty. Specifically, the US Department of Agriculture (7) has designated the location of this study, Athens County, Ohio, as being high in poverty, and the Appalachian Regional Commission (8), based on the economic indicators of unemployment, per capita market income, and poverty, has designated it as [economically] distressed, their most severe economic level category.

Food insecurity is negatively associated with several nutritional and nonnutritional outcomes, including health (9). One construct, social capital, has been defined as "a measure of trust, reciprocity, and social networks" (10) or a perceived sense of social trust and community reciprocity (11). At the household level, social capital can positively 
influence food insecurity (10) and health (12). A food assistance safety net has been developed to improve food access of individuals and families in the United States. To improve health and food security, the Special Supplemental Nutrition Program for Women, Infants, and Children (WIC) provides supplemental nutritious foods, nutrition education and counseling, and health screening and referrals to eligible households (185\% US Poverty Income Guidelines) (13). WIC Farmers' Market Nutrition Program was developed to provide fresh, unprepared, locally grown fruits, vegetables, and herbs to WIC participants and to expand the awareness about, use of, and sales at farmers' markets (14). In 2005, Ohio Farmers' Market Nutrition Program participants received $\$ 18$ in coupons for the season. For example, a household with a participating mother and one child received $\$ 36$ in coupons (personal communication, Athens County WIC office). The Farmers' Market Nutrition Program has the potential to positively impact not only dietary quality $(15,16)$, food insecurity, and health, but also social capital, because the Farmers' Market Nutrition Program encourages participants to utilize community-based food networks.

No studies have examined the impact of the Farmers' Market Nutrition Program participation on both food security status and social capital, and only one study has examined the relationship of food security status to social capital (10). Therefore, using a sample of women at risk for food insecurity, the purposes of this study were to examine the household food security status, level of social capital, and perceived health status; and assess the relationships between these factors.

\section{METHODS}

\section{Study Design and Sample}

The Ohio Department of Health, Columbus, and the Ohio University Office of Research Compliance, Athens, approved this cross-sectional survey prior to data collection. Surveys written in English, along with a cover letter explaining the purposes of the study and postage-paid envelope to return the survey within 2 weeks, were mailed to all women $(n=1,076)$ who were participating in, or responsible for communication related to a household member's participation in, the Athens County, Ohio, WIC program in November, 2005. Because of resource constraints, a follow-up reminder was not mailed, and no compensation was provided to respondents.

\section{Survey Instrument}

Two survey versions were mailed; one to women from households participating in WIC alone, and one to those from households participating in both WIC and the Farmers' Market Nutrition Program. (Note: Eligibility is the same for WIC and the Farmers' Market Nutrition Program; however, not all WIC clients choose to participate in the Farmers' Market Nutrition Program.) Both survey versions included three validated measures:

- the 18-item US Household Food Security Survey Module to assess food security status $(2,17)$;

- a perceived individual health status question (poor, fair, good, very good, excellent) (18); and
Table 1. Questions used to measure social capital and scores of women from households participating in WIC ${ }^{\mathrm{a}}$ and those from households participating in both WIC and WIC FMNPb

Questions used to measure social capital (11)

People around here are willing to help their neighbors

This is a close-knit or tight neighborhood (community), where people generally know one another

If I had to borrow $\$ 30.00$ in an emergency, I could borrow it from a neighbor

People in this neighborhood (community) generally do not get along with each other

People in this neighborhood can be trusted

If I were sick, I could count on my neighbors to stop for groceries for me

People in this neighborhood (community) do not share the same values

\begin{tabular}{l}
\hline Respondents' Social Capital Scores \\
\hline
\end{tabular}

- a 7-item measure of social capital (Table 1), which assessed factors related to neighborhood security, interactions, and trust (11).

Food Security Survey Module $(2,17)$ and social capital $(10,11)$ measures were scored using standardized methods.

\section{Statistical Analyses}

Data were computed using the Statistical Program for Social Sciences (SPSS, version 13.0, 2004, Chicago, IL), with missing data or nonapplicable responses scored as missing data. Descriptive statistics were utilized to summarize sample characteristics, including level of education. The Pearson $\chi^{2}$ test was conducted when multiple answers to survey questions were possible, to determine if group status was independent from response. With quantitative response, independent sample $t$ tests were performed to determine if a difference in means existed 


\begin{tabular}{|c|c|c|c|c|c|c|c|c|c|}
\hline \multirow[b]{2}{*}{ Group } & \multicolumn{9}{|c|}{ Household Food Security Status Category } \\
\hline & $\mathrm{n}$ & $\%$ & $n$ & $\%$ & $\mathrm{n}$ & $\%$ & $n$ & $\%$ & Total \\
\hline \multicolumn{10}{|c|}{$\begin{array}{l}\text { "WIC=Special Supplemental Nutrition Program for Women, Infants, and Children. } \\
{ }^{0} \mathrm{FMNP=} \text { Farmers' Market Nutrition Program. } \\
\text { "The 'food security" category in this study signifies no indication of food insecurity, while the •at risk for food insecunty category signifies that one or two affirmative response/indicators } \\
\text { of food inseculity were provided by the respondent in us national estimates of food insecurity }(2,16) \text {, these two categories are combined into one category (food secure). Food security } \\
\text { (national category) by study group and total sample are noted in supersclipts e through g. } \\
\text { dformerty food insecure without hunger. } \\
{ }^{\circ} \text { Food security (national category): } n=82(49.1 \%) \text {. } \\
\text { 'Food security (national category): } n=26(42.6 \%) \text {. } \\
\text { 9food seculity (national category): } n=108(47.4 \%) \text {. }\end{array}$} \\
\hline
\end{tabular}

for WIC compared to the Farmers' Market Nutrition Program (two-sided $P$ value reported.) Lastly, Spearman correlation was used for quantitative associations between two variables. $P$ value $<0.05$, set a priori, was used to identify statistical significance for subsequent research and confirmation, because of the exploratory nature of the study.

\section{RESULTS AND DISCUSSION}

Of 1,076 women surveyed, 235 usable surveys were returned, reflecting an overall response rate of $21.8 \%$ $(20.4 \%[n=170 / 829]$ for WIC group participants and 26.4\% [n=65/246] for WIC/Farmers' Market Nutrition Program group participants). Of those from both groups $(\mathrm{N}=235), 55.6 \%(\mathrm{n}=130)$ were married, $14.5 \% \quad(\mathrm{n}=34)$ were currently pregnant, and $10.8 \%(\mathrm{n}=25)$ were currently breastfeeding. Single women with children composed $44.2 \%(n=97)$ of the sample. On average, household size was 3.69:tl.30 members. Of 232, 87.3\% ( $=202)$ had the equivalent of a high school education, and $51.1 \%$ $(n=120)$ had pursued or completed education after high school. Women participating in the Farmers' Market Nutrition Program reported higher levels of education $(\mathrm{P}=0.027)$, but no other differences $(\mathrm{P}>0.05)$ were noted between groups for these characteristics.

In sum, household food insecurity was inversely associated with both perceived health status and social capital among women living in WIC households. Table 2 summarizes the household food security status ofrespondents. Household food security status did not differ between the groups $(1=2.117, P=0.548)$. Only one household was classified as having very low food security among children $(0.4 \%)$. Overall, WIC households represented in this study were more food insecure (52.6\%) than households in the United States in 2005 (11.0\%), in the state of Ohio in 2003 to 2005 (12.6\%), located in rural areas $(12.0 \%)$, and with an annual income $<185 \%$ of the poverty level (28.3\%) (2). The greater rate of food insecu- rity seen was not unexpected, in view of the characteristics of the sample, as well as the previous studies that have shown households in Appalachian Ohio to experience high rates of food insecurity (4-6,19). Despite receiving additional resources by participating in the Farmers' Market Nutrition Program, the program has limited benefits (\$18 per person participating). This amount of additional resources does not appear to be adequate to alleviate food insecurity.

Regarding perceived health status, of 232 respondents, $10.3 \%(n=24)$ perceived their health status to be poor/ fair, $43.1 \%(n=100)$ perceived their health status to be good, $33.6 \%(n=78)$ perceived their health status to be very good, and $12.9 \%(n=30)$ perceived their health to be excellent. Perceived health status $(1=4.619$, $\mathrm{P}=0.202$ ) did not differ between WIC and Farmers' Market Nutrition Program groups. However, among all respondents, household food insecurity was negatively associated with perceived health status $(r=-0.229$, $\mathrm{P}=0.001$ ). The negative association of food insecurity to health status was also not unexpected, in view of previous studies, both in the Appalachian region of Ohio $(4,6)$ and elsewhere (20-23). The position of the American Dietetic Association on food insecurity and hunger in the United States (9) summarized that food insecurity can have grave consequences, including negative physical, psychological, and sociofamilial outcomes. It appears that improving access to food may improve the health of Americans. For qualifying households, the WIC program can not only provide improved access to food, but also access to nutrition education and other health care and social services (13), which may improve food security-related outcomes.

As noted in Table 1 , high social capital was greater $\left(x^{2}=8.156, P=0.004\right)$ among WIC group respondents, compared to WIC/Farmers' Market Nutrition Program group respondents. In fact, WIC respondents were 69\% more likely to have high social capital, as compared to 
WIC/Farmers' Market Nutrition Program households. Among all respondents, food security was positively associated with social capital $(r=0.337, P<0.001)$. It was surprising that WIC/Farmers' Market Nutrition Program participants had lower levels of social capital, that is, they perceived a lesser sense of social trust and community reciprocity (10), than those not participating in the Farmers' Market Nutrition Program. This finding could be attributed to WIC/Farmers' Market Nutrition Program group respondents having fewer social connections within the community, precipitating a need for additional assistance. Social capital appears to increase the likelihood of access to social support in times of need (12). In addition, in the study area, Farmers' Market Nutrition Program participants typically receive their Farmers' Market Nutrition Program vouchers at the farmers' market WIC booth, rather than receiving them upon WIC registration, which may be perceived by clients as a modified form of "begging." Anecdotally, while food stamps are accepted at the farmers' market, as are the Farmers' Market Nutrition Program vouchers, most customers pay cash for items at the market. Farmers' Market Nutrition Program coupons could give participants and others at the farmers' market the perception that users of the coupons are from a family with a low income. It is possible that the poorer social capital seen in the WIC/Farmers' Market Nutrition Program group could also be attributed to: 1) the culture/atmosphere of the farmers' market where the Farmers' Market Nutrition Program coupons may be redeemed; and/or 2) feelings of disgrace associated with receiving food assistance. Receiving Farmers' Market Nutrition Program vouchers when registering for the WIC program, rather than at a public marketplace lacking privacy, may be a more effective alternative for voucher dispersal. Yet, distributing the vouchers at the market may improve redemption rates, because of particular barriers to redeeming vouchers, such as lack of transportation to the market.

A limitation of the study was that participants might not represent the targeted sample (women living in WIC households in Athens County, Ohio), because of the nonprobability sampling strategy, lack of survey follow-up reminder, low response rate, and the possibility that women with a greater interest in food and nutrition may have been more likely to complete the survey. In addition, although this study was conducted in a rural Appalachian county, Ohio University is located in Athens, possibly skewing education levels and not representing the entire region accurately. Additional limitations of the study include the fact that some members of the sample may have had issues with literacy, which may have posed a limitation because of the self-administered nature of the survey; and the survey was only conducted at the end of the Farmers' Market Nutrition Program season, rather than using a pre- and posttest design, which prohibits attributing results to participation in the Farmers' Market Nutrition Program program.

\section{CONCLUSIONS}

Additional research is needed to clarify the relationship of food security, social capital, and self-rated health both in Ohio and across the United States. In view of these findings, future researchers should use a pre- and post- test design to evaluate the impact of Farmers' Market Nutrition Program participation on household food security, social capital, and perceived health status to further evaluate these trends.

As noted in the position of the American Dietetic Association regarding food insecurity and hunger in the United States (9), registered dietitians and dietetics technicians "can play a key role in ending food insecurity and hunger." These and other nutrition and health professionals should be aware of the implications of food insecurity. In addition, while nutrition education is vital for inclusion in all food assistance programs, rather than focusing on programming related solely to food acquisition and nutrition, food and nutrition professionals should consider developing programs that strengthen social capital. For example, individuals and families that know and trust their neighbors may be more inclined to share food or transportation to the supermarket, as well as share child-care responsibilities (10), enabling and empowering individuals to network and form their own support programs and projects with their community. Encouraging clients to participate in a social or civic organization within their community may improve social capital (10). In addition, offering nutrition education programs that are linked to community-based activities, and developing community-based mentoring programs may improve social capital.

$\overline{\text { Funding for this study was from the School of Human and }}$ Consumer Sciences, Graduate Student Senate, and Ohio University Research Council, Ohio University, Athens.

\section{References}

1. Anderson S. Core indicators of nutritional state for difficult to sample populations. J Nutr. 1990;102:1559-1660.

2. Nord M, Andrews M, Carlson S. Household Food Security in the United States, 2005. (ERR-29). Washington, DC: US Department of Agriculture, Economic Research Service; 2006.

3. Bartfield J, Dunifon R, Nord M, Carlson S. What Factors Account for State-to State Differences in Food Security? (EIB-20). Washington, DC: US Department of Agriculture, Economic Research Service; 2006.

4. Holben DH, Pheley AM. Diabetes risk and obesity in food-insecure households in rural Appalachian Ohio [serial online]. Prev Chronic Dis. 2006;3 [Cited June 29, 2006]. Available at: http://www.cdc.gov/ pcd/issues/2006/jul/05_0127.htm. Accessed September 12, 2007.

5. Holben DH, McClincy MC, Holcomb JP, Dean KL, Walker CE. Food security status of households in Appalachian Ohio with children in Head Start. J Am Diet Assoc. 2004;104:238-241.

6. Pheley AM, Holben DH, Graham AS, Simpson C. Food security and perception of health status: A preliminary study in rural Appalachia. J Rural Health. 2002;18:447-454.

7. Rural-Urban Continuum Codes. Alexandria, VA: United States Department of Agriculture, Economic Research Service; 2003. Available at: http://www.ers.usda.gov/data/ruralurbancontinuumcodes/. Accessed December 8, 2006.

8. Appalachian Regional Commission. Washington, DC: Appalachian Regional Commission. Available at: http://www.arc.gov. Accessed December 8, 2006.

9. Position of the American Dietetic Association: Food insecurity and hunger in the United States. J Am Diet Assoc. 2006;106:446-458.

10. Martin KS, Rogers BL, Cook JT, Joseph HM. Social capital is associated with decreased risk of hunger. Soc Sci Med. 2004;58: 2645-2654.

11. Sampson R, Raudenbush S, Earls F. Neighborhoods and violent crime: A multilevel study of collective efficacy. Science. 1997;277:918-924.

12. Kawachi I, Kennedy BP, Glass R. Social capital and self-rated health: A contextual analysis. Am J Public Health. 1999;89:1187-1193.

13. WIC Program. Available at: http://www.fns.usda.gov/wic/. Accessed December 8, 2006. 
14. WIC Farmers' Market Nutrition Program. Available at: http://www fns.usda.gov/wic/FMNP/FMNPfaqs.htm. Accessed December 8, 2006

15. Herman DR, Harrison GG, Jenkins E. Choices made by low-income women provided with an economic supplement for fresh fruit and vegetable purchase. J Am Diet Assoc. 2006;106:740-744.

16. Kropf ML, Holben DH, Holcomb JP Jr, Anderson H. Food security status and produce intake and behaviors of Special Supplemental Nutrition Program for Women, Infants, and Children and Farmers Market Nutrition Program participants. J Am Diet Assoc. 2007;107: 1903-1908.

17. Bickel G, Nord M, Price C, Hamilton W, Cook J. Guide to Measuring Household Food Security: Revised 2000. Alexandria, VA: US Department of Agriculture, Food and Nutrition Service; 2000.

18. Ware JJ, Sherbourne CD. The MOS 36-item short-form health survey (SF-36). I. Conceptual framework and item selection. Med Care. 1992; 30:473-483.
19. Gorimani ET, Holben DH. WIC program participants in rural Appalachia may be prone to food insecurity: A pilot study. J Am Diet Assoc. 1999;99(suppl):A25.

20. Nelson K, Cunningham W, Andersen R, Harrison G, Gelberg L. Is food insufficiency associated with health status and health care utilization among adults with diabetes? J Gen Intern Med. 2001;16:404411.

21. Siefert K, Heflin CM, Corcoran ME, Williams DR. Food insufficiency and the physical and mental health of low-income women. Women Health. 2001;32:159-177.

22. Stuff JE, Casey PH, Szeto KL, Gossett JM, Robbins JM, Simpson PM, Connell C, Bogle ML. Household food insecurity is associated with adult health status. $J$ Nutr. 2004;134:2330-2335.

23. Vozoris NT, Tarasuk VS. Household food insufficiency is associated with poorer health. J Nutr. 2003;133:120-126.

Post-print standardized by MSL Academic Endeavors, the imprint of the Michael Schwartz Library at Cleveland State University, 2017 